\title{
Planktic Cyanobacteria from upper Tietê basin reservoirs, SP, Brazil
}

\author{
CÉLIA L. SANT'ANNA ${ }^{1,3}$, SILVIA S. MELCHER ${ }^{1}$, MARIA DO CARMO CARVALHO ${ }^{2}$, \\ MARCINA P. GEMELGO ${ }^{1}$ and MARIA TERESA DE P. AZEVEDO ${ }^{1}$
}

(received: March 31, 2005; accepted: November 30, 2006)

\begin{abstract}
Planktic Cyanobacteria from upper Tietê basin reservoirs, SP, Brazil). Considering the great ecological and sanitary importance of the cyanobacteria and the need of detailed information about these organisms in Brazilian water bodies, the present study aims at contributing towards the knowledge of the cyanobacterial flora of five reservoirs belonging to the upper Tietê Basin, São Paulo: Billings, Guarapiranga, Jundiaí, Pirapora, Ponte Nova and Taiaçupeba. In the past several years, these reservoirs have been submitted to severe environmental deterioration and have repeatedly presented cyanobacterial blooms, including those of toxic species. The samples were collected between 1997 and 2003 either with plankton net (20 $\mu \mathrm{m}$ mesh) or van Dorn's bottle, and preserved with lugol solution or formaldehyde. Some species were isolated and maintained in culture. Forty-eight species of cyanobacteria were identified, with predominance of the order Chroococcales (58\%), followed by the orders Oscillatoriales (21\%) and Nostocales (21\%). Among the 48 studied species, 17 (35\%) were considered potentially toxic. The occurrence and biodiversity of the cyanobacteria in each reservoir depend on the environmental conditions. Among the five water bodies, Billings Reservoir presented the most adequate situation for the development of a greater number of species (34), probably due to its high $\mathrm{pH}$ values (around 8). Pirapora Reservoir on the other hand, with highest conductivity $\left(445.0 \mu \mathrm{S} \mathrm{cm}^{-1}\right)$ and lowest Secchi depth values $(0.2 \mathrm{~m})$, presented the lowest cyanobacterial biodiversity (14 species).
\end{abstract}

Key words - Brazil, diversity, planktic Cyanobacteria, reservoirs

RESUMO - (Cianobactérias planctônicas em reservatórios do Alto Tietê, SP, Brasil). Diante da grande importância ecológica e sanitária das cianobactérias e da escassez de informações mais detalhadas sobre estes organismos em corpos d'água doce brasileiros, o presente trabalho pretende estudar a flora de cianobactérias em cinco represas da Bacia Hidrográfica do Alto Tietê, São Paulo. As represas Billings, Guarapiranga, Jundiaí, Pirapora, Ponte Nova e Taiaçupeba vêm sofrendo, nos últimos anos, forte deterioração ambiental e têm apresentado repetidas florações de cianobactérias, inclusive tóxicas. As amostras foram coletadas entre 1997 e 2003 com rede de plâncton (abertura da malha de $20 \mu \mathrm{m}$ ) ou garrafa do tipo van Dorn, e preservadas com lugol ou formalina. Algumas espécies foram isoladas e mantidas em cultura. Foram identificadas 48 espécies de cianobactérias, com predominância da ordem Chroococcales (58\%), seguida das ordens Oscillatoriales (21\%) e Nostocales (21\%). Entre as 48 espécies estudadas, 17 (35\%) são consideradas potencialmente tóxicas. A biodiversidade e distribuição das cianobactérias em cada reservatório relacionam-se com as condições ambientais dos mesmos. A Represa Billings mostrou-se o ambiente mais propício ao desenvolvimento de maior número de espécies (34), provavelmente em função de seu pH elevado (em torno de 8). Já o Reservatório de Pirapora, com os valores mais altos de condutividade $\left(445,0 \mu \mathrm{S} \mathrm{cm} \mathrm{cm}^{-1}\right)$ e a transparência mais baixa (0,2 m), apresentou baixa biodiversidade de cianobactérias (14 espécies).

Palavras-chave - Brasil, Cianobactérias planctônicas, diversidade, represas

\section{Introduction}

In the past several years, growing record of cyanobacterial blooms all over the world has increased the concern about their harmful effects on water quality and public health. Frequently associated with eutrophic water conditions (Dokulil \& Teubner 2000, Huszar et al. 2000), the dominance of cyanobacteria can be related to environmental factors such as high total phosphorus

\footnotetext{
1. Instituto de Botânica, Seção de Ficologia, Caixa Postal 3005 , 01061-970 São Paulo, SP, Brazil.

2. Companhia de Tecnologia de Saneamento AmbientalCETESB, Av. Frederico Hermann Jr., 345, 05489-900 São Paulo, SP, Brazil.

3. Corresponding author: celiasant@ig.com.br
}

(Watson et al. 1997), high temperature (Shapiro 1990), high pH (Caraco \& Miller 1998), low light (Smith 1986) and low total nitrogen (Smith 1983). Many species are well known producers of toxic compounds (Carmichael 1996, Sant'Anna et al. 2004) as well as of substances causing unpleasant taste and odor to drinking water (Persson 1996).

Despite their great environmental and sanitary importance, biodiversity of cyanobacteria is almost unknown in very large areas of South America (Bouvy et al. 2000, Azevedo et al. 2003, Tundisi 2003). Even in the state of São Paulo, southeastern Brazil, where the country's highest population densities caused severe deterioration of water quality, only few studies to describe the cyanobacterial flora of continental water bodies have been conducted. Some works which include 
description of planktic cyanobacteria of São Paulo are: Sant'Anna \& Azevedo (1995), Azevedo et al. (1996), Sant'Anna \& Azevedo (2000), Komárek et al. (2002), Azevedo et al. (2003), Sant'Anna et al. (2004). Concerning the upper Tietê basin, which comprises important reservoirs responsible for supplying several millions of people with drinking water, no previous work to describe the cyanobacterial flora has been published yet, although frequent cyanobacterial blooms were observed during the last decade. The region is, except for the Billings and Guarapiranga reservoirs (Beyruth 2000, Carvalho 2003), still very scarcely known. Therefore, considering the key role of cyanobacteria in water quality problems and the need of detailed studies about these organisms, this study aims to contribute towards the knowledge of the cyanobacterial flora and its distribution in the upper Tietê reservoirs.

\section{Material and methods}

Five hydrographic basins form the upper Tietê region, whose main rivers are the Tietê, Pinheiros, Guarapiranga, Tamanduateí and Cotia. This complex system supplies drinking water to over 20 million people and to the largest industrial center in the country, the metropolitan area of São Paulo (Cetesb 1996). Some features of the studied reservoirs are shown in table 1.

At least 10 samples were collected in each reservoir between 1997 and 2003, either with plankton net $(20 \mu \mathrm{m}$ mesh) or with van Dorn's bottle. They were preserved with lugol solution or $4 \%$ formaldehyde. Part of the samples was kept in culture. The culture conditions were BG-11 and/or ASM-1 media, temperature of $22 \pm 1^{\circ} \mathrm{C}$, irradiances of 20 to $25 \mu \mathrm{mol}$ photons $\mathrm{m}^{-2} \mathrm{~s}^{-1}$ with $14-10$ hours light-dark cycle. The studied unialgal cultures are maintained in the Algal Culture Collection of the Botanical Institute of São Paulo (SPC).

The samples were analyzed and photographed with a Zeiss Axioplan 2 Microscope with coupled camera. At least 15 individuals of each species were measured.

The system of Komárek \& Anagnostidis (1989, 1999, 2005) was adopted for species classification and identification. Species already described for São Paulo State in Sant'Anna et al. (2004) were listed in table 2.

\section{Results and Discussion}

\section{CHROOCOCCALES}

Chroococcaceae

Chroococcus limneticus Lemmermann, Forschungsber.

Biol. Stat. Plön 7:132. 1898.

Figure 1
Colonies microscopic, usually 4-32-celled, with cells slightly distant from one another or in 2-4-celled groups irregularly spread in the mucilage; mucilage tenuous, hyaline, diffuse, forming a wide margin around the cells; cells spherical or hemispherical, 5.5-7.0 $\mu \mathrm{m}$ in diameter; cell content blue-green, without aerotopes.

Selected material: BRAZIL. São PAULO: São Paulo, Billings Reservoir, 22-XI-2000, M.C. Carvalho s.n. (SP355906).

Chroococcus minutus (Kützing) Nägeli, Neue Denkschr. der Allg. Schweiz. Gesellsch. Gesamt. Naturwiss. 10(7):46. 1849.

Basionym: Protococcus minutus Kützing, Phycol. Gen.:168. 1843.

Figure 2

Cells solitary or forming microscopic colonies with 2-8 cells; mucilage thin, hyaline; cells spherical or hemispherical, 5.0-7.5 $\mu \mathrm{m}$ in diameter; cell content bluegreen, without aerotopes.

Selected material: BRAZIL. São PAuLo: São Paulo, Billings Reservoir, 22-V-1998, C.L. Sant'Anna s.n. (SP336725).

Merismopediaceae

Aphanocapsa nubilum Komárek \& H. J. Kling, Arch. Hydrobiol./Algolog. Stud. 61:24. 1991.

Figure 3

Colonies small, more or less spherical; mucilage hyaline, diffluent, following the approximate cell outline; cells spherical, more or less aggregated, 1.2-2.0 $\mu \mathrm{m}$ in diameter; cell content blue-green, without aerotopes.

Selected material: BRAZIL. São PAULo: São Paulo, Guarapiranga Reservoir, 21-VIII-2001, C.L. Sant'Anna s.n. (SP355910).

Coelomoron tropicalis Senna, A. C. Peres \& Komárek, Nova Hedwigia 67:96. 1998.

Figure 8

Colonies rounded, usually $16-24 \mu \mathrm{m}$ in diameter, with cells radially distributed on the colony's surface; cells ovoid, 1.4-3.0 $\mu \mathrm{m}$ long, 1.4-2.8 $\mu \mathrm{m}$ wide; cell content blue-green, without aerotopes.

Selected material: BRAZIL. São PAULO: Mogi das Cruzes, Jundiaí Reservoir, 23-X-2003, S.S. Melcher s.n. (SP365620).

Snowella lacustris (Chodat) Komárek \& Hindák, Arch. Hydrobiol./Algolog. Stud. 50-53:203. 1988. 


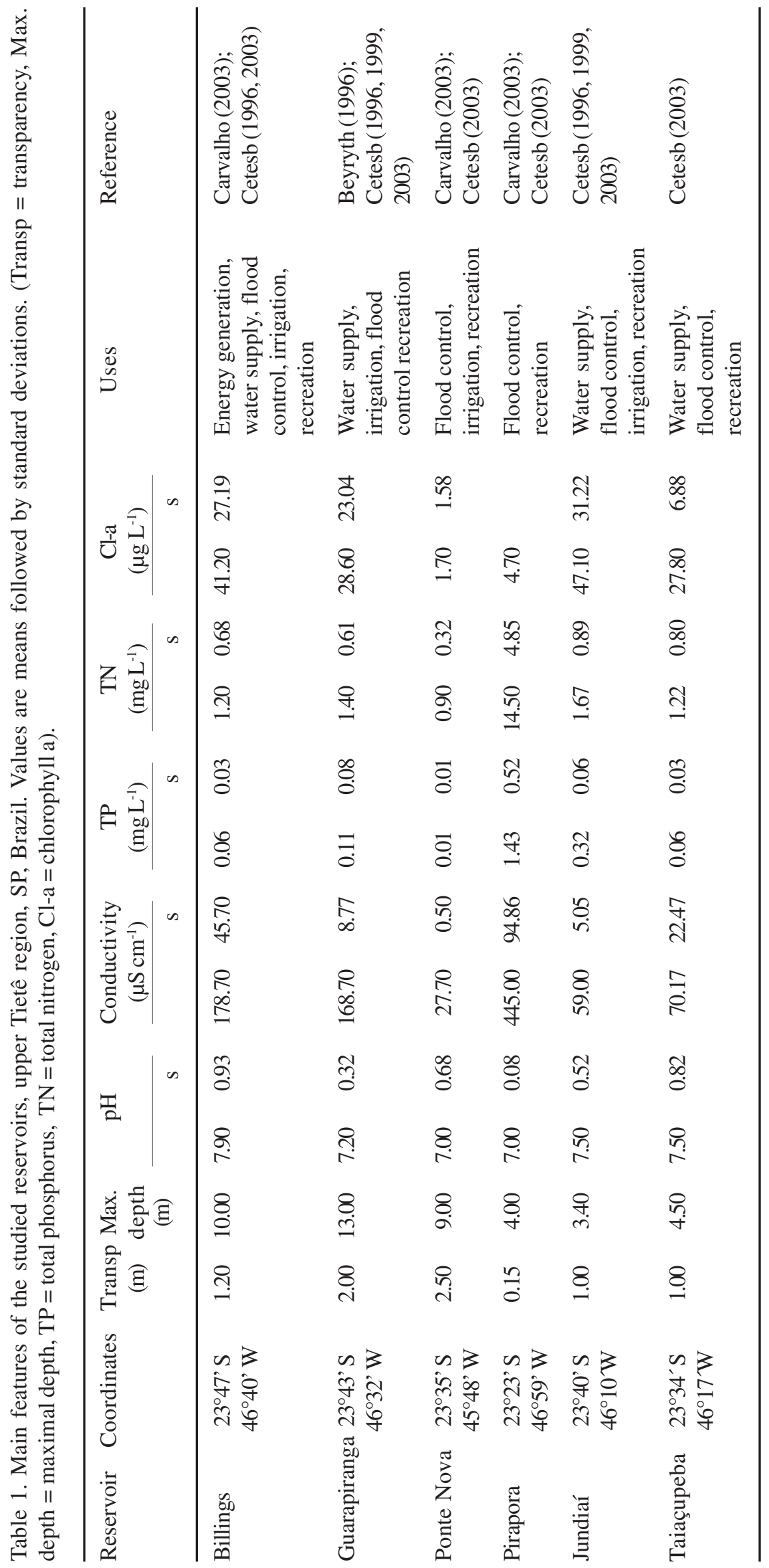


Table 2. Cyanobacteria already described for São Paulo State (Sant'Anna et al. 2004).

\begin{tabular}{|c|c|c|}
\hline Taxa & Occurence in the Upper Tietê Reservoirs & Figure \\
\hline \multicolumn{3}{|l|}{ CHROOCOCCALES } \\
\hline \multicolumn{3}{|l|}{ Chroococcaceae } \\
\hline Chroococcus dispersus (Keissler) Lemmermann 1904 & Billings, Ponte Nova & 32 \\
\hline \multicolumn{3}{|l|}{ Merismopediaceae } \\
\hline Aphanocapsa delicatissima W. West \& G. S. West, 1912 & $\begin{array}{l}\text { Billings, Guarapiranga, Jundiaí, Ponte Nova, } \\
\text { Pirapora, Taiaçupeba }\end{array}$ & 33 \\
\hline Aphanocapsa elachista W. West \& G. S. West 1894 & Billings, Guarapiranga, Ponte Nova & 34 \\
\hline $\begin{array}{l}\text { Aphanocapsa holsatica (Lemmermann) Cronberg \& } \\
\text { Komárek } 1994\end{array}$ & Billings & 35 \\
\hline $\begin{array}{l}\text { Aphanocapsa incerta (Lemmermann) Cronberg \& Komárek } \\
1994\end{array}$ & Guarapiranga & 36 \\
\hline Aphanocapsa koordersii Strøm 1923 & Billings, Pirapora & 37 \\
\hline $\begin{array}{l}\text { Coelosphaerium evidenter-marginatum M. T. P. Azevedo \& } \\
\text { Sant'Anna } 1999\end{array}$ & Billings & 38 \\
\hline Merismopedia punctata Meyen 1839 & Billings, Guarapiranga & 39 \\
\hline Merismopedia tenuissima Lemmermann 1898 & Billings, Guarapiranga, Jundiaí, Ponte Nova & 40 \\
\hline $\begin{array}{l}\text { Sphaerocavum brasiliense M. T. P. Azevedo \& } \\
\text { Sant'Anna } 2003\end{array}$ & Billings, Jundiaí, Taiaçupeba & 41 \\
\hline \multicolumn{3}{|l|}{ Microcystaceae } \\
\hline Microcystis aeruginosa (Kützing) Lemmermann 1907 & $\begin{array}{l}\text { Billings, Guarapiranga, Jundiaí, Ponte Nova, } \\
\text { Pirapora, Taiaçupeba }\end{array}$ & $42 b$ \\
\hline Microcystis botrys Teiling 1942 & Billings & 44 \\
\hline Microcystis panniformis Komárek et al. 2002 & Billings, Guarapiranga, Jundiaí, Taiaçupeba & 45 \\
\hline Microcystis protocystis Crow 1923 & Billings, Guarapiranga, Jundiaí, Taiaçupeba & 46,47 \\
\hline Microcystis wesenbergii Komárek 1968 & Jundiaí, Pirapora, Ponte Nova, Taiaçupeba & 48 \\
\hline \multicolumn{3}{|l|}{ Synechococcaceae } \\
\hline $\begin{array}{l}\text { Radiocystis fernandoi Komárek \& Komárková- } \\
\text { Legnerová } 1993\end{array}$ & Billings, Guarapiranga, Ponte Nova, Taiaçupeba & 49 \\
\hline Rhabdoderma lineare Schmidle \& Lauterborn 1900 & Ponte Nova & 50 \\
\hline
\end{tabular}

Basionym: Gomphosphaeria lacustris Chodat, Bull. l'herbier Boissier 6:180. 1898.

Figure 9

Colonies spherical or elongated, with cells arranged on the colony's surface; cells connected by thin but distinct mucilaginous stalks; colonial envelope hyaline, inconspicuous, forming a wide margin around groups of cells; cells ovoid, 2.5-3.8 $\mu \mathrm{m}$ long, 2.0-3.5 $\mu \mathrm{m}$ wide; cell content blue-green, without aerotopes.

Selected material: BRAZIL. São PAUlo: Mogi das Cruzes, Jundiaí Reservoir, 23-X-2003, S.S. Melcher s.n. (SP365620).

Synechocystis aquatilis Sauvageau, Bull. Soc. Bot. France 39:121. 1892.

Figure 10

Cells solitary or in pairs, spherical, 4-6 $\mu \mathrm{m}$ in diameter; cell content blue-green, without aerotopes.
Selected material: BRAZIL. São PAULO: São Paulo, Billings Reservoir, 22-V-1998, C.L. Sant'Anna s.n. (SP336725).

Woronichinia naegeliana (Unger) Elenkin, Acta Inst. Bot. Acad. Sci. USSR, Ser. 2(1):17. 1933.

Basionym: Coelosphaerium naegelianum Unger, Denkschr. Ak. Wissensch. Wien 7. 1854.

Figure 11

Colonies spherical or elongated, with cells radially distributed on the colony's surface and connected by persistent tubular mucilaginous stalks, which form the typical radial lamellation in the center of the colony; mucilage hyaline, inconspicuous, forming a wide margin around groups of cells; cells ovoid, 5-7 $\mu \mathrm{m}$ long, 3.5-4.0 $\mu \mathrm{m}$ wide; cell content dark green, with aerotopes.

Selected material: BRAZIL. São PAULO: São Paulo, Billings Reservoir, 7-XI-2002, M.C.P. Gemelgo s.n. (SP365616). 


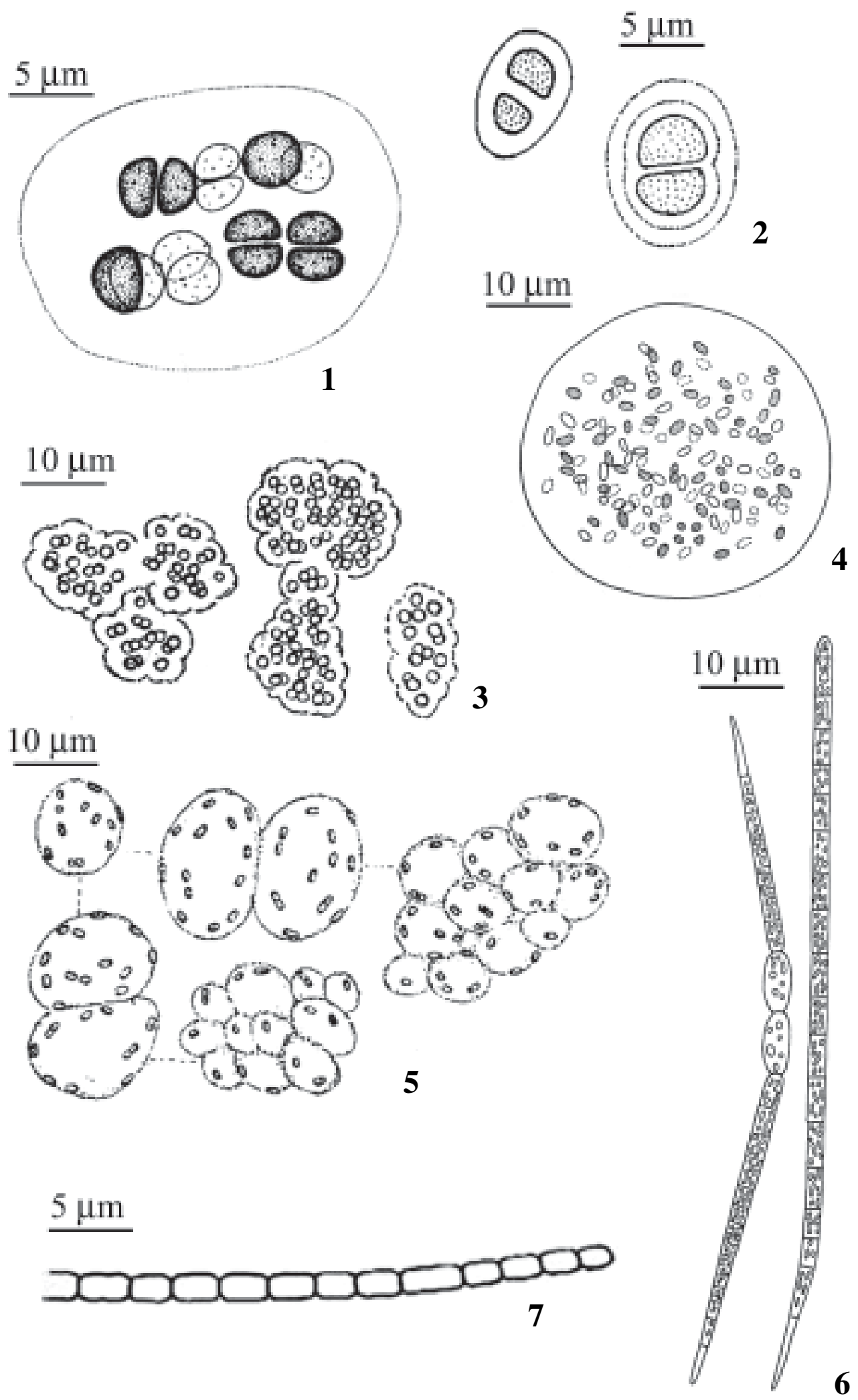

Figures 1-7. Planktic cyanobacteria from upper Tietê basin reservoirs, SP, Brazil. 1. Chroococcus limneticus. 2. C. minutus. 3. Aphanocapsa nubilum. 4. Aphanothece smithii. 5. Epigloesphaera glebulenta. 6. Raphidiopsis mediterranea. 7. Pseudanabaena catenata. (1 according to Werner 1988; 3 according to Komárek \& Kling 1991; 5 according to KomárkováLegnerová 1991; 2, 4, 6 and 7 according to Werner 2002). 
Synechococcaceae

Aphanothece smithii Komárková-Legnerová \& Cronberg, Arch. Hydrobiol./Algolog. Stud. 72:13. 1994. Figure 4

Colonies spherical, elongated or irregular, cells more or less regularly distributed in the mucilage; mucilage hyaline, diffluent; cells oval, 2-3 $\mu \mathrm{m}$ long, 1.0-1.5 $\mu \mathrm{m}$ wide; cell content blue-green, sometimes with small aerotopes.

Selected material: BRAZIL. SÃo PAULO: Salesópolis, Ponte Nova Reservoir, 5-VI-1998, M.C. Carvalho s.n. (SP365631).

Cyanodictyon iac Cronberg \& Komárek, Hydrobiol./ Algolog. Stud. 75:323. 1994.

Figure 12

Colonies spherical, lobate or irregular; mucilage hyaline, diffluent; cells oval, after division rounded, arranged in short rows on the colony's surface, 1.5-2.0 $\mu \mathrm{m}$ long, 1.0-1.4 $\mu \mathrm{m}$ wide; cell content pale bluegreen, without aerotopes.

Selected material: BRAZIL. São PAULO: Salesópolis, Ponte Nova Reservoir, 5-VI-1998, M.C. Carvalho s.n. (SP365631).

Epigloeosphaera glebulenta (Zalessky) KomárkováLegnerovová, Arch. Hydrobiol./Algolog. Stud. 62:7.1991. Basionym: Aphanothece glebulenta Zalessky, Rev. Génér. Bot. 38:31. 1926.

Figure 5

Colonies rouded to elliptical; mucilage hyaline, homogeneous; cells oval, disposed at the outer surface of the mucilage, 1.5-2.0 $\mu \mathrm{m}$ long, 1.0-1.4 $\mu \mathrm{m}$ wide; cell content blue-green, without aerotopes.

Selected material: BRAZIL. SÃo PAULO: Pirapora do Bom Jesus, Pirapora Reservoir, 7-III-1998, M.C. Carvalho s.n. (SP365632).

Synechococcus nidulans (E. G. Pringsheim) Komárek, in P. C. Bourrelly, Les Algues d'Eau Douce, III: 690. 1970.

Basionym: Lauterbornia nidulans Pringsheim, Arch. Mikrobiol. 63. 1968.

Figure 13

Cells isolated, rarely forming short filaments, oval or cylindrical, straight, curved or sigmoid, without mucilage, 1.5-6.0 $\mu \mathrm{m}$ long, 0.5-2.0 $\mu \mathrm{m}$ wide; cell content pale blue-green, homogeneous, without aerotopes.

Selected material: BRAZIL. São PAUlo: São Paulo, Guarapiranga Reservoir, 10-IV-2002, M.C.P. Gemelgo s.n. (SP365619).

\section{NOSTOCALES}

Nostocaceae

Anabaena circinalis Rabenhorst, Allg. Eur.:209. 1852. Figure 14

Trichomes solitary, rarely entangled, regularly or irregularly coiled, distance between the coils $25-50 \mu \mathrm{m}$, spirals 75-100 $\mu \mathrm{m}$ wide; sheath narrow, diffluent; cells spherical or barrel shaped, 7.5-12.0 $\mu \mathrm{m}$ long, 8-13 $\mu \mathrm{m}$ wide, with aerotopes; heterocytes more or less spherical, 9-12 $\mu \mathrm{m}$ in diameter; akinetes cylindrical when mature, isolated or in pairs, distant from the heterocytes, 18-25 $\mu \mathrm{m}$ long, 14-23 $\mu \mathrm{m}$ wide; epispore smooth.

Selected material: BRAZIL. SÃo PAUlo: São Paulo, Billings Reservoir, 7-XI-2002, M.C.P. Gemelgo s.n. (SP365616).

Anabaena crassa (Lemmermann) KomárkovaLegnerová \& Cronberg, Arch. Hydrobiol./ Algol. Stud. 67, Suppl. 95:24. 1992.

Basionym: Anabaena spiroides var. crassa Lemmermann, Bot. Centralbl. 76:155. 1898.

Figure 15

Trichomes solitary, regularly coiled, distance between the coils 30-52 $\mu \mathrm{m}$, spirals 60-70 $\mu \mathrm{m}$ wide; sheath wide, diffluent; cells spherical or barrel shaped, 9.5-12.0 $\mu \mathrm{m}$ long, 9-12 $\mu \mathrm{m}$ wide, with aerotopes; heterocytes more or less spherical, 12-14 $\mu \mathrm{m}$ in diameter; akinetes elliptical, distant from the heterocytes, 20-25 $\mu$ m long, 14-17 $\mu$ m wide, epispore smooth.

Selected material: BRAZIL. SÃo PAUlo: Mogi das Cruzes, Jundiaí Reservoir, 18-V-2004, S.S. Melcher s.n. (SP365623).

Anabaena planctonica Brunnthaler, Sitz. Ak. Wiss. Wien 112:1. 1903.

Figure 16

Trichomes solitary, straight or slightly curved; sheath hyaline, up to $30 \mu \mathrm{m}$ wide; cells barrel shaped, generally shorter than wide, 4.5-7.0 $\mu \mathrm{m}$ long, 10-14 $\mu \mathrm{m}$ wide, with aerotopes; heterocytes more or less spherical, 10-12 $\mu \mathrm{m}$ in diameter; akinetes elliptical, isolated or in pairs, distant from the heterocytes, 18-26 $\mu \mathrm{m}$ long, 12-18 mm wide; epispore smooth.

Selected material: BRAZIL. São PaUlo: Suzano, Taiaçupeba Reservoir, 1-IV-2004, S.S. Melcher s.n. (SP365624).

Anabaena solitaria Klebahn, Flora 80:270. 1895. Figure 17 
Trichomes solitary, straight; sheath hyaline, up to $20 \mu \mathrm{m}$ wide; cells barrel-shaped, longer than wide, 6.5-12.0 $\mu \mathrm{m}$ long, 6-10 mm wide, with aerotopes; heterocytes more or less spherical, 8-10 $\mu \mathrm{m}$ in diameter; akinetes cylindrical when mature, isolated, distant from the heterocytes, 25-35 $\mu \mathrm{m}$ long, 17-19 $\mu \mathrm{m}$ wide; epispore smooth.

Selected material: BRAZIL. São Paulo: Suzano, Taiaçupeba Reservoir, 1-IV-2004, S.S. Melcher s.n. (SP365624).

Anabaena spiroides Klebahn, Flora 80:26. 1895. Figure 18

Trichomes solitary, sometimes entangled, coiled, distance between the coils 30-48 $\mu \mathrm{m}$, spirals $30-40 \mu \mathrm{m}$ wide; sheath wide, hyaline; cells more or less spherical, 6.5-8.0 $\mu \mathrm{m}$ in diameter, with aerotopes; heterocytes more or less spherical, 6-7 $\mu \mathrm{m}$ in diameter; akinetes ovate when mature, single, rarely in pairs, distant from the heterocytes, 13-18 $\mu \mathrm{m}$ long, 6.5-9.0 $\mu \mathrm{m}$ wide; epispore smooth.

Selected material: BRAZIL. São PAULO: São Paulo, Billings Reservoir, 4-XII-2002, M.C.P. Gemelgo s.n. (SP365617).

Aphanizomenon gracile Lemmermann, Krypt. Fl. Mark Brandenb. 5:193. 1910.

Figure 19

Trichomes straight, constricted, gradually attenuated; cells cylindrical, 5-7 $\mu \mathrm{m}$ long, 2.3-3.5 $\mu \mathrm{m}$ wide; heterocytes elliptical with truncate apex, 5-7 $\mu \mathrm{m}$ long, 3.5-5.0 $\mu \mathrm{m}$ wide; apical cell capitate or cylindrical with rounded apex, 4.5-5.7 $\mu \mathrm{m}$ long, 2-3 $\mu \mathrm{m}$ wide; akinetes not observed; cell content blue-green, with aerotopes.

Selected material: BRAZIL. São PAULO: São Paulo, Billings Reservoir, 4-XII-2002, M.C.P. Gemelgo s.n. (SP365617).

Aphanizomenon tropicalis Horecká et Komárek, Preslia 51:289. 1979.

Figures 20-21

Trichomes straight, not constricted; cells cylindrical 3.0-5.4 $\mu \mathrm{m}$ long, 8.7-10.5 $\mu \mathrm{m}$ wide; heterocytes rounded to elliptical, rarely cylindrical, $7 \mu \mathrm{m}$ long, $3 \mu \mathrm{m}$ wide; apical cell narrowed, elongated, conical, 9.6-21.0 $\mu \mathrm{m}$ long. 3-4 $\mu \mathrm{m}$ wide; akinetes not observed; cell content blue-green, with aerotopes.

Occurrence: Billings, Taiaçupeba

Selected material: BRAZIL. São PAULO: São Paulo, Billings Reservoir, 7-XI-2002, M.C.P. Gemelgo s.n. (SP365616); Suzano, Taiaçupeba Reservoir, 18-V-2004,

\section{S.S. Melcher s.n. (SP365622).}

Cylindrospermopsis raciborskii (Woloszynska) Seenayya \& Subba Raju, in Desikachary, Tax. and biol. of blue-green algae 55. 1972.

Basionym: Anabaena raciborskii Wolozynska, Bull. Int. Acad. Sci. Lett. Cracovie, Ser. B:684. 1912. Figure 22

Trichomes solitary, straight or slightly curved, constricted or not; cells cylindrical, 7-11 $\mu \mathrm{m}$ long, 2-3 $\mu \mathrm{m}$ wide, with aerotopes; apical cell acute conical; heterocytes always terminal, conical, single, $10-13 \mu \mathrm{m}$ long, 3-5 $\mu \mathrm{m}$ wide; akinetes cylindrical, distant from the heterocytes by some cells, 13-16 $\mu \mathrm{m}$ long, 4-5 $\mu \mathrm{m}$ wide.

Selected material: BRAZIL. São PAULO: São Paulo, Guarapiranga Reservoir, 14-II-2002, M.C.P. Gemelgo s.n. (SP365618); Mogi das Cruzes, Jundiaí Reservoir, 18-V-2004, S.S. Melcher s.n. (SP365623).

Raphidiopsis brookii P. J. Hill, Phycologia 11(2):213. 1972.

Figure 23

Trichomes solitary, straight or slightly curved, not constricted, attenuated toward the ends; cells cylindrical, 5-12 $\mu \mathrm{m}$ long, 2-3 $\mu \mathrm{m}$ wide, with aerotopes; apical cell acuminated; heterocytes always absent; akinetes subterminal, cylindrical with rounded ends, $6-8 \mu \mathrm{m}$ long, 3-4 $\mu \mathrm{m}$ wide, single or in pairs.

Selected material: BRAZIL. São PAULO: São Paulo, Guarapiranga Reservoir, 14-II-2002, M.C.P. Gemelgo s.n. (SP365618).

Raphidiopsis mediterranea Skuja, Hedwigia 77:23. 1937.

Figure 6

Trichomes solitary, straight or slightly curved, not constricted, attenuated toward the ends; cells cylindrical, 2-10 $\mu \mathrm{m}$ long, 1.0-2.5 $\mu \mathrm{m}$ wide, with aerotopes; apical cell acuminated; heterocytes always absent; akinetes subterminal or intercalary, ellipsoid with rounded ends, 6.5-13.0 $\mu \mathrm{m}$ long, 2.5-3.0 $\mu \mathrm{m}$ wide, single or in pairs.

Selected material: BRAZIL. São PAULo: São Paulo, Billings Reservoir, 14-VII-2004, Cetesb s.n. (SP365635).

\section{OSCILLATORIALES}

Phormidiaceae

Planktothrix agardhii (Gomont) Komárek \& Anagnostidis, Arch. Hydrobiol./Algolog. Stud. Suppl. 80(1-4):416. 1988. 
Basionym: Oscillatoria agardhii Gomont, Ann. Sci. Nat. Bot Series 7 (15):205. 1892.

Figure 24

Trichomes solitary, straight, not constricted, slightly attenuated; cells isodiametric or shorter than wide, 2.5-4.0 $\mu \mathrm{m}$ long, 4-5 $\mu \mathrm{m}$ wide; apical cell capitated or not; cell content blue-green, with aerotopes; motility present.
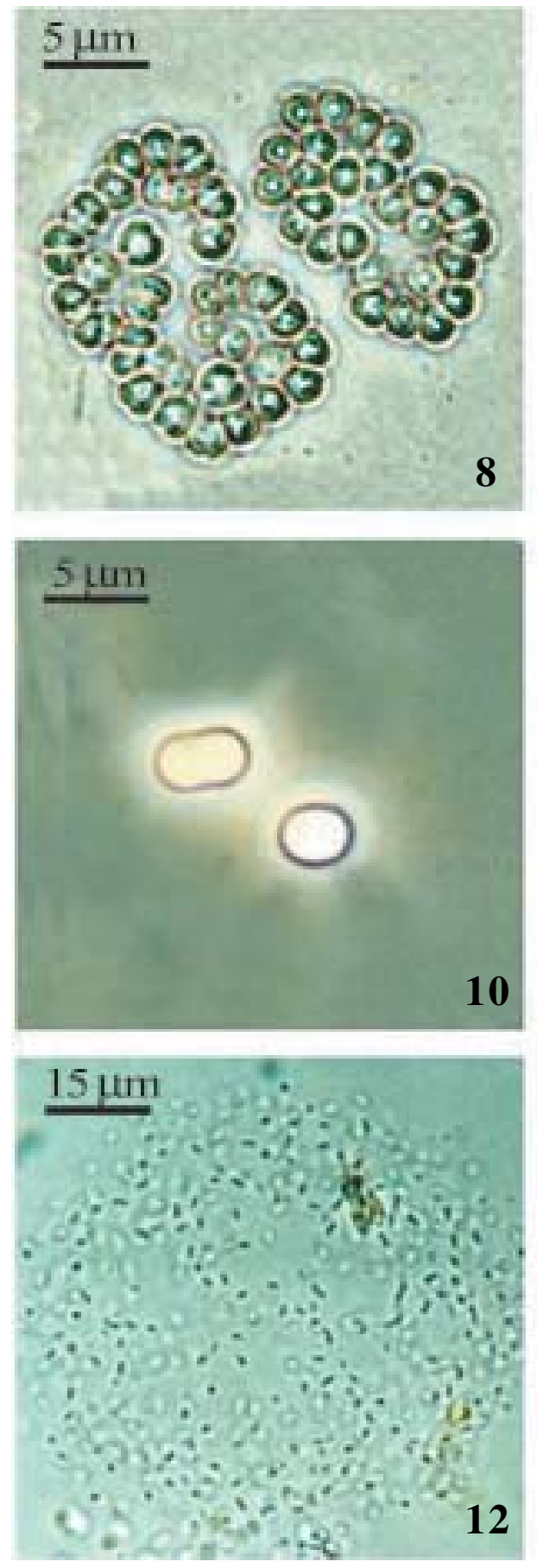

Selected material: BRAZIL. São PAULO: São Paulo, Billings Reservoir, 7-XI-2002, M.C.P. Gemelgo s.n. (SP365616); Suzano, Taiaçupeba Reservoir, 18-V-2004, S.S. Melcher s.n. (SP365622).

Planktothrix mougeotii (Gomont) Komárek \& Anagnostidis, Arch. Hydrobiol./Algolog. Stud. 50-53, Suppl. 80(1-4):416. 1988.
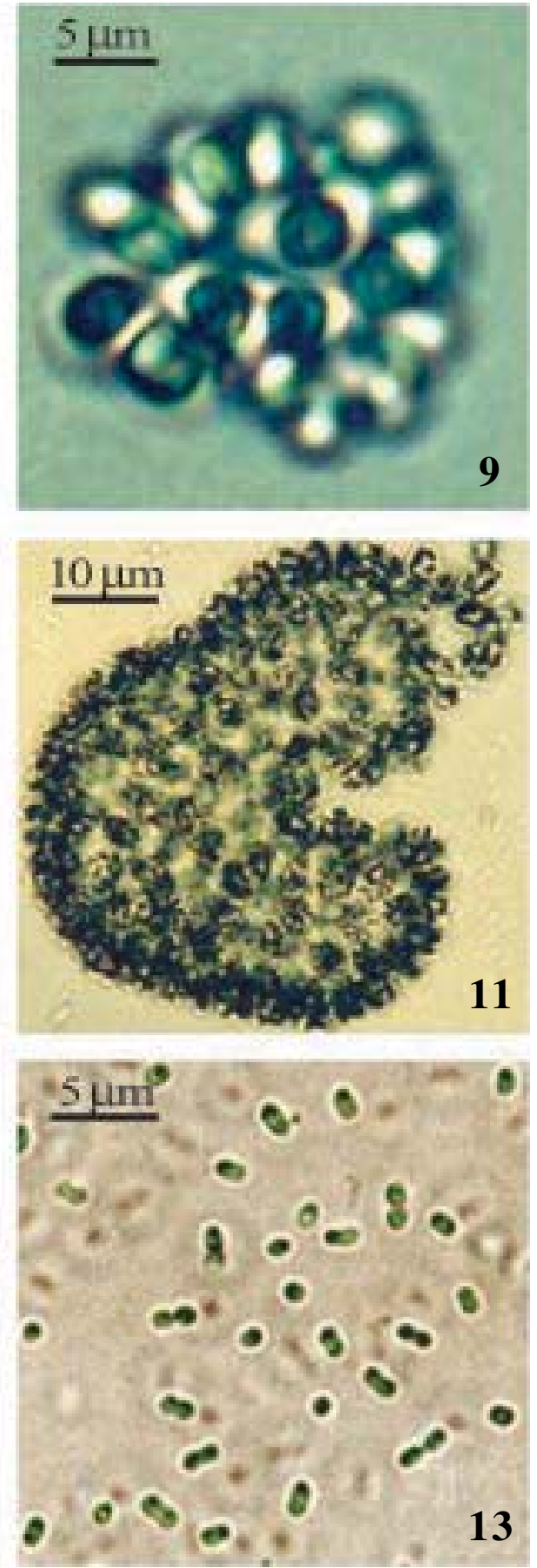

Figures 8-13. Planktic cyanobacteria from upper Tietê basin reservoirs, SP, Brazil. 8. Coelomoron tropicalis. 9. Snowella lacustris. 10. Synechocystis aquatilis. 11. Woronichinia naegeliana. 12. Cyanodictyon iac. 13. Synechococcus nidulans. 
Basionym: Oscillatoria mougeotii Gomont, Ann. Sci. Nat. Bot. Series 7 (15):230. 1892.

Figure 25

Trichomes solitary, straight, not constricted, not attenuated; cells shorter than wide, 2.5-4.0 $\mu \mathrm{m}$ long, 5-6 $\mu \mathrm{m}$ wide; apical cell rounded; cell content blue-green, with aerotopes; motility present.
Selected material: BRAZIL. São PAULO: São Paulo, Billings Reservoir, 24-III-2004, Cetesb s.n. (SP365634), 14-VII-2004 (SP365635).

Pseudanabaenaceae

Geitlerinema amphibium (Gomont) Anagnostidis, Pl. Syst. Evol. 164:35. 1989.
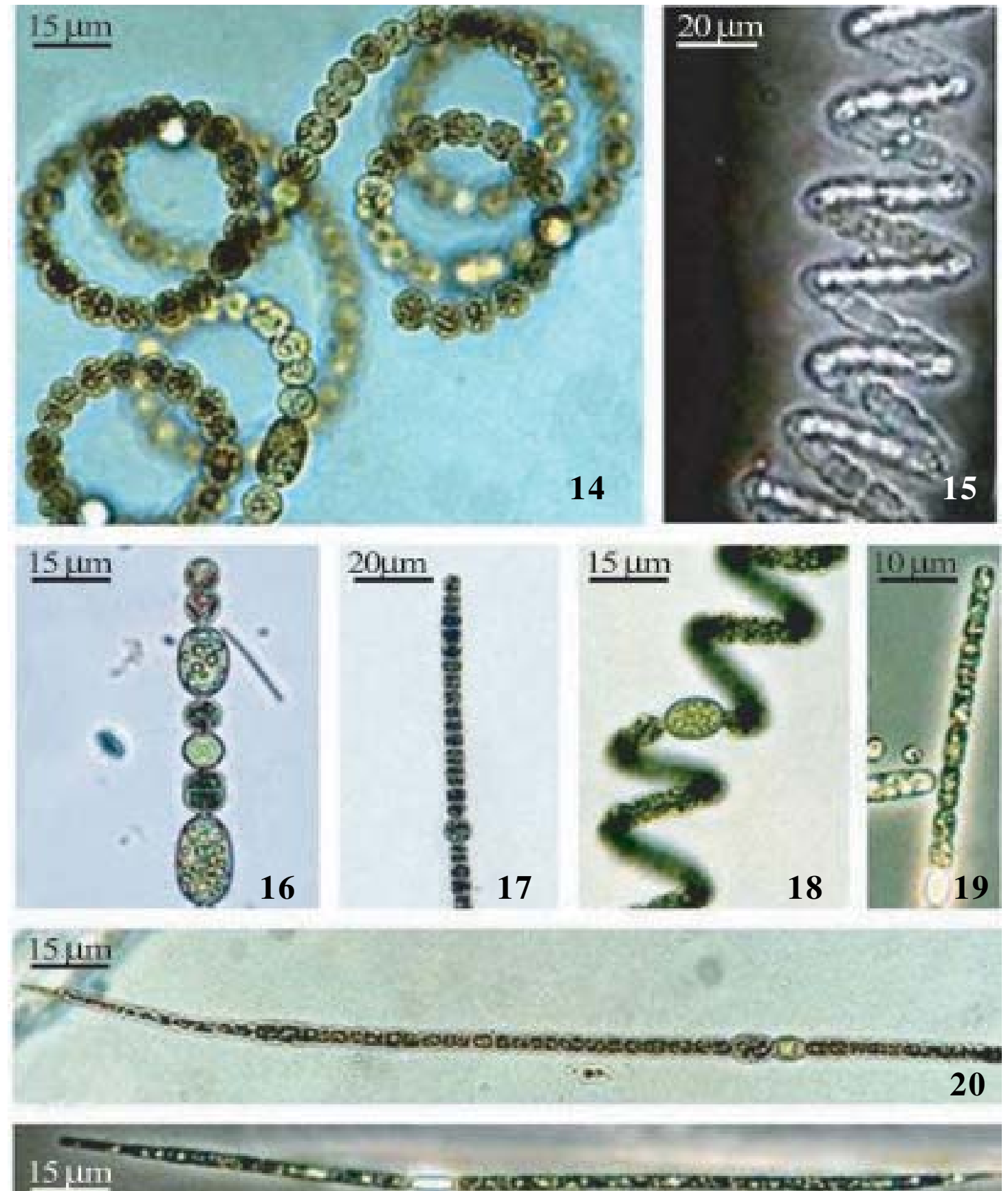

Figures 14-21. Planktic cyanobacteria from upper Tietê basin reservoirs, SP, Brazil. 14. Anabaena circinalis. 15. A. crassa. 16. A. planctonica. 17. A. solitaria. 18. A. spiroides. 19. Aphanizomenon gracile. 20-21. A. tropicalis. 
Basionym: Oscillatoria amphibia Gomont, Ann. Sci. Nat. Bot Series 7(15):221. 1892.

Figure 26

Trichomes flexuous, isolated, not constricted, not attenuated; cells isodiametric or longer than wide, 2-7 $\mu \mathrm{m}$ long, 2-3 $\mu \mathrm{m}$ wide; apical cell cylindrical with rounded end; cross wall with 1-2 granules; cell content bluegreen, homogeneous; motility present.

Selected material: BRAZIL. São PAULo: São Paulo, Guarapiranga Reservoir, 21-VIII-2001, C.L. Sant'Anna s.n. (SP355910).

Geitlerinema splendidum (Gomont) Anagnostidis, P. Syst. Evol. 164:35. 1989.

Basionym: Oscillatoria splendida Gomont, Ann. Sci. Nat. Bot Series 7(15):224. 1892.

Figure 27

Trichomes straight or slightly coiled, 2.0-3.1 $\mu \mathrm{m}$ wide, not constricted; ends of the trichomes more or less bent, attenuated, sometimes screw-like or in a sickle; cells 2-4 times longer than wide, 3-9 $\mu$ m long, containing cyanophycin granules; apical cell striking attenuated, spherically capitated; aerotopes absent; sheaths never found; intense wavelike motility.

Selected material: BRAZIL. São PAULO: São Paulo, Guarapiranga Reservoir, 10-IV-2002, M.C.P. Gemelgo s.n. (SP365619).

Geitlerinema unigranulatum (Rana N. Singh) Komárek \& M. T. P. Azevedo, Arch. Hydrobiol./ Algolog. Stud. 99, Suppl. 134(1):39. 2000.

Basionym: Oscillatoria punctata var. unigranulata R. N. Singh, Proc. Indian Acad. Sci. 9:68. 1939.

Figure 28

Trichomes flexuous, isolated or in groups, not constricted, not attenuated; cells longer than wide, 2.5-7.0 $\mu \mathrm{m}$ long, 1.0-1.8 $\mu \mathrm{m}$ wide; apical cell cylindrical with rounded end; cross wall indistinct, with 1 granule; cell content blue-green, homogeneous; motility present.

Selected material: BRAZIL. São PAULO: São Paulo, Guarapiranga Reservoir, 14-II-2002, M.C.P. Gemelgo s.n. (SP365618).

Limnothrix planctonica (Woloszynska) Meffert, Arch. Hydrobiol./Algolog. Stud., Suppl. 80:269. 1988.

Basionym: Oscillatoria planctonica Woloszynska, Bull. Ac. Sc. Cracovie:530. 1912.

Figure 29

Trichomes straight, isolated, slightly constricted, not attenuated; cells cylindrical, 5-7 $\mu \mathrm{m}$ long, 1.7-2.0 $\mu \mathrm{m}$ wide; apical cell cylindrical with rounded end; cross wall not granulated; aerotopes disposed at cells poles or in the cell center; cell content blue-green; motility not observed.

Selected material: BRAZIL. São PAULO: São Paulo, Guarapiranga Reservoir, 14-II-2002, M.C.P. Gemelgo s.n. (SP365618).

Planktolyngbya limnetica (Lemmermann) Komárková-Legnerová \& Cronberg, Arch. Hydrobiol./ Algolog. Stud. 67, Suppl. 90:21. 1992.

Basionym: Lyngbya limnetica Lemmermann, Bot. Centralbl. (76):154. 1898.

Figure 30

Filaments isolated, generally straight, sometimes curved, not constricted, not attenuated; sheath hyaline, cells cylindrical, $2-3 \mu \mathrm{m}$ long, 1.0-1.6 $\mu \mathrm{m}$ wide; apical cell cylindrical with rounded end; cross wall not granulated; cell content blue-green, homogeneous.

Selected material: BRAZIL. São PAULO: São Paulo, Guarapiranga Reservoir, 21-VIII-2001, C.L. Sant'Anna s.n. (SP355910).

Pseudanabaena catenata Lauterborn, Verh. Naturhist.-Mediz. Ver. Heidelberg, N.F. 13(2):437. 1915. Figure 7

Trichomes flexuous, isolated, constricted, not attenuated; cells longer than wide, 2.5-5.0 $\mu \mathrm{m}$ long, 1.8-2.6 $\mu \mathrm{m}$ wide; apical cell cylindrical with rounded end; cross wall not granulated; cell content blue-green, homogeneous.

Selected material: BRAZIL. São PAULO: São Paulo, Guarapiranga Reservoir, 10-IV-2002, M.C.P. Gemelgo s.n. (SP365619).

Pseudanabaena galeata Böcher, Det. Kgl. Dansk. Vidensk. Selsk. Biol. Med. 21:1. 1949.

Figure 31

Trichomes short (4-8 cells), isolated, straight or slightly curved, constricted, not attenuated; cells cylindrical, 3-7 $\mu \mathrm{m}$ long, 1.8-2.3 $\mu \mathrm{m}$ wide; apical cell cylindrical, with cupola-like polar aerotope (arrows); cross wall with aerotopes; cell content blue-green.

Selected material: BRAZIL. São PaUlo: São Paulo, Billings Reservoir, 14-VII-2004, Cetesb s.n. (SP365635).

Pseudanabaena mucicola (Naumann \& HubberPestalozzi) P. C. Bourrelly, Les Algues d'Eau Douce, III:440. 1970. 
Basionym: Phormidium mucicola Naumann \& HuberPestalozzi, Ber. Dt. Bot. Gesellsch. 47:86. 1929.

Figures $42 \mathrm{a}-43$

Trichomes endogloeic, short (3-6 cells), isolated, constricted; cells cylindrical, 2.5-5.0 $\mu \mathrm{m}$ long, 1.8-2.6 $\mu \mathrm{m}$ wide; apical cell conical; cross wall not granulated; cell content blue-green, homogeneous.

Selected material: BRAZIL. São PAULO: São Paulo,
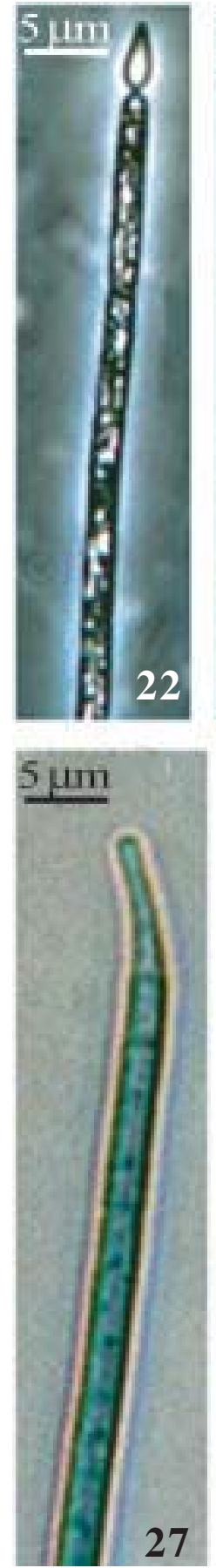
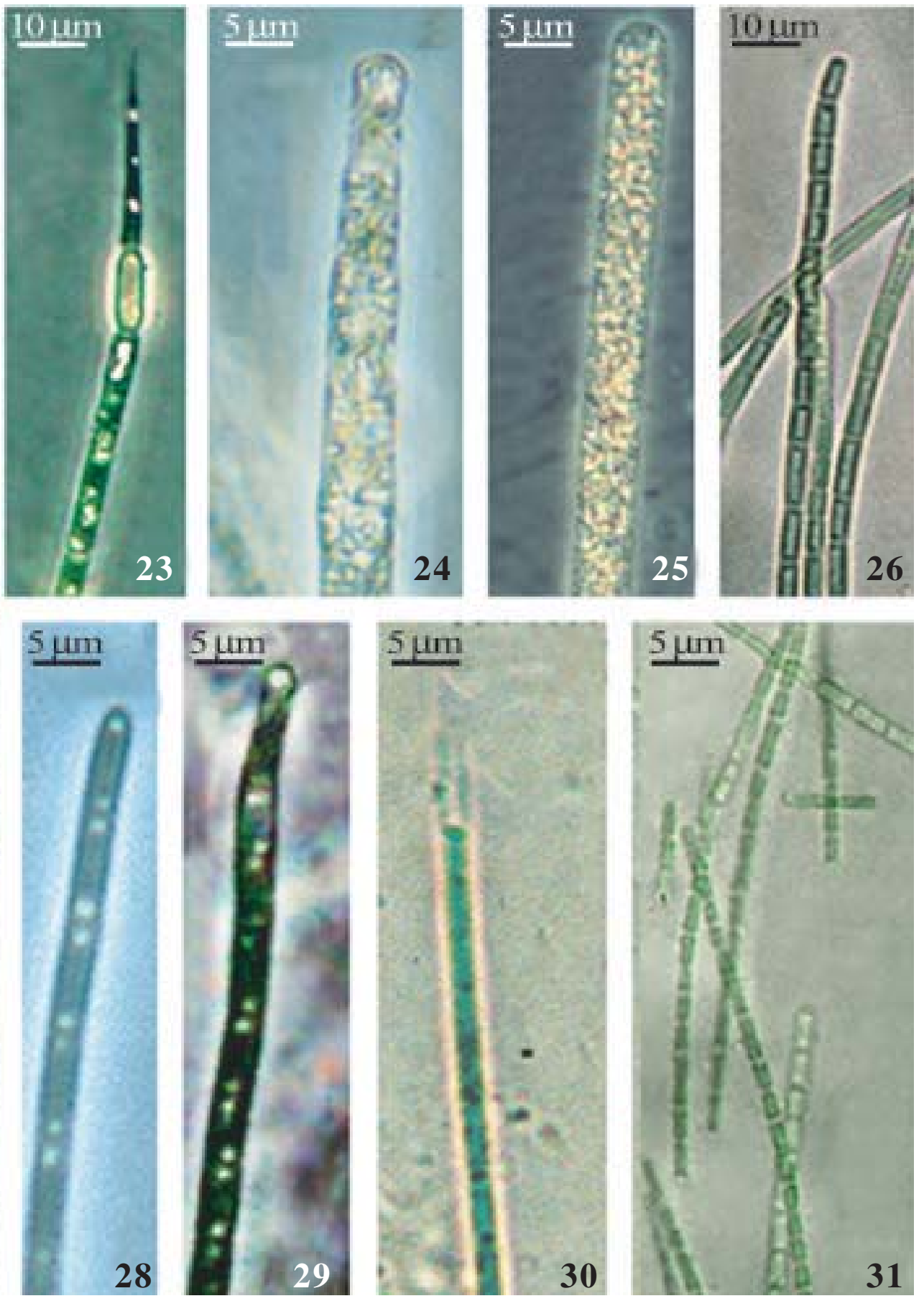

Figures 22-31. Planktic cyanobacteria from upper Tietê basin reservoirs, SP, Brazil. 22. Cylindrospermopsis raciborskii. 23. Raphidiopsis brookii. 24. Planktothrix agardhii. 25. P. mougeotii. 26. Geitlerinema amphibium. 27. G. splendidum. 28. G. unigranulatum. 29. Limnothrix planctonica. 30. Planktolyngbya limnetica. 31. Pseudanabaena galeata. 
Billings Reservoir, 4-XII-2002, M.C.P. Gemelgo. s.n. (SP365617).

Forty-eight species of cyanobacteria, including those listed in table 2 (figures 32-42 and 44-50) that are described in Sant'Anna et al. (2004), were identified: 28 (58\%) belong to the Order Chroococcales, $10(21 \%)$ to the Order Oscillatoriales and $10(21 \%)$ to the Order Nostocales (figure 51a). The proportion of each group varies in the different reservoirs. The only observed pattern is the overall
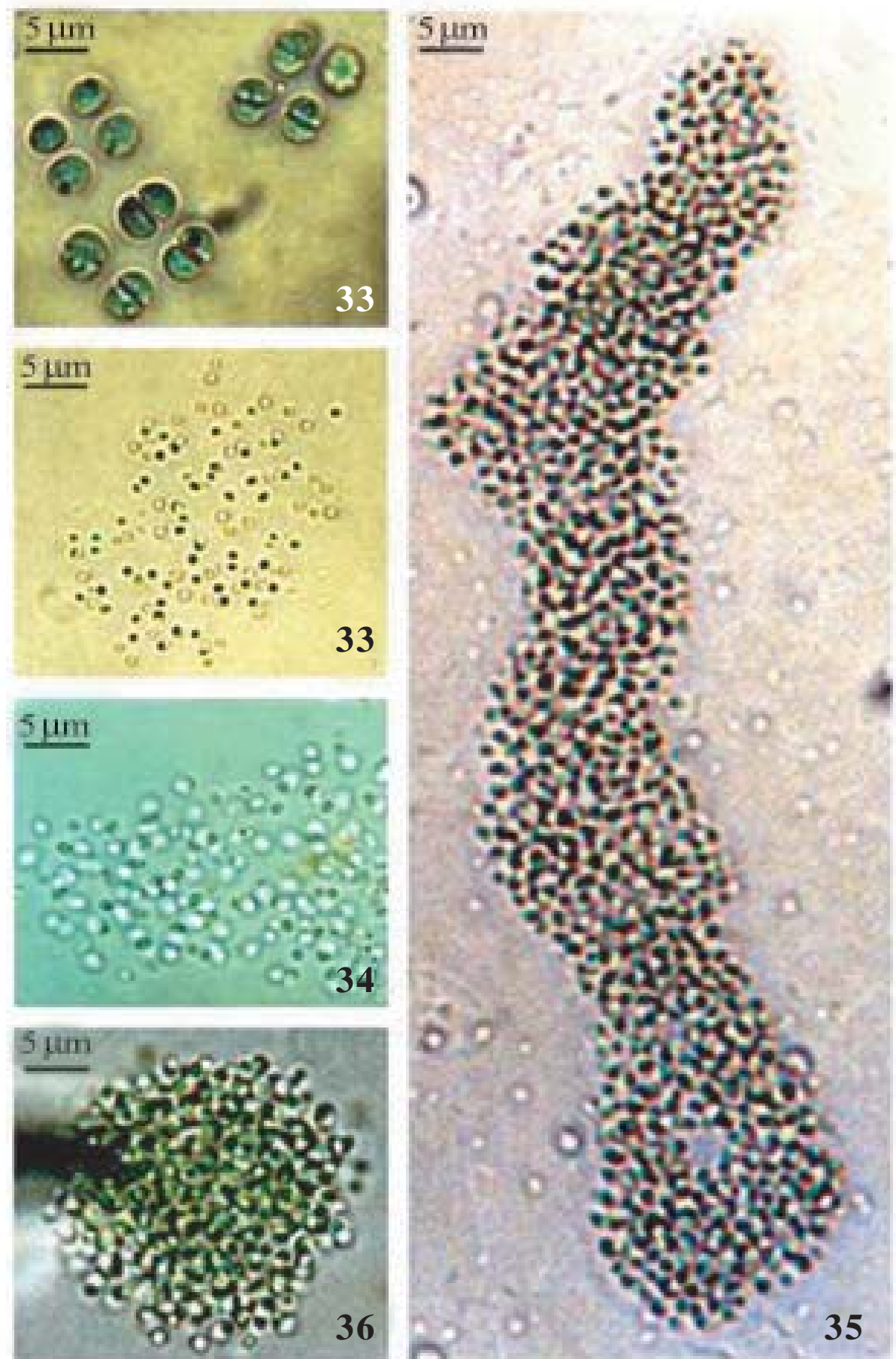

Figures 32-36. Planktic cyanobacteria from upper Tietê basin reservoirs, SP, Brazil. 32. Chroococcus dispersus. 33. Aphanocapsa delicatissima. 34. A. elachista. 35. A. holsatica. 36. A. incerta. 
dominance of coccoid cyanobacteria, as far as species richness is concerned. The highest species richness was observed in Billings Reservoir, whereas the lowest in Pirapora Reservoir (figure 51b). Some general features of the reservoirs based on literature data (table
1) evidenced some differences. Billings is the only reservoir with high $\mathrm{pH}$ values (around 8), which directly affect the carbon balance towards $\mathrm{CO}_{3}$ production (Shapiro 1990, Oliver \& Ganf 2000). This situation favors cyanobacterial development and is
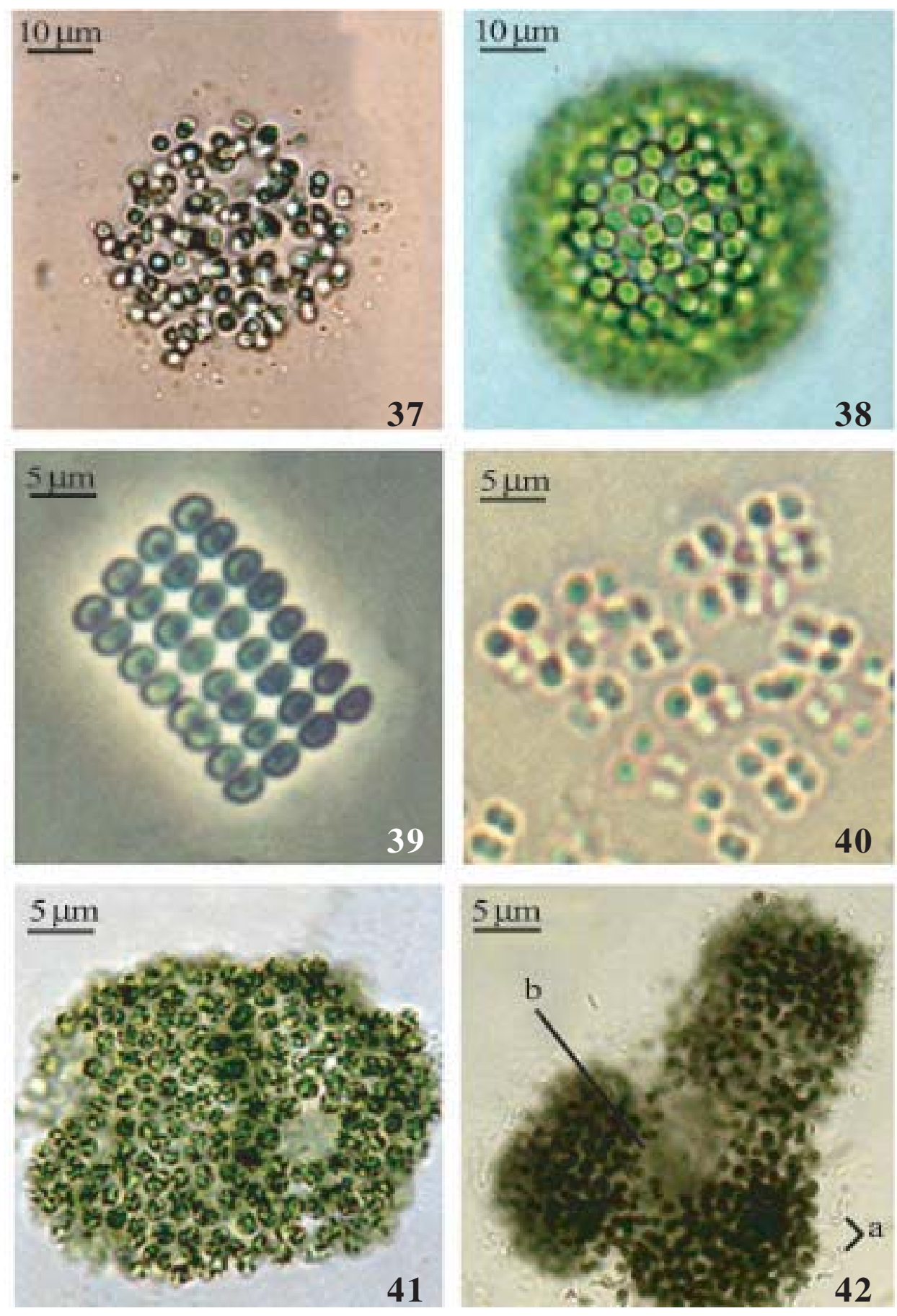

Figures 37-42. Planktic cyanobacteria from upper Tietê basin reservoirs, SP, Brazil. 37. Aphanocapsa koordersii. 38. Coelosphaerium evidenter-marginatum. 39. Merismopedia punctata. 40. M. tenuissima. 41. Sphaerocavum brasiliense. 42a. Pseudanabaena mucicola. 42b. Microcystis aeruginosa. 
harmful to other phytoplanktonic groups (Shapiro 1990). In spite of its high conductivity values, the reservoir presents high transparency (1.2 m Secchi depth), consequently, its euphotic zone is relatively deep and allows the production of high biomass. Furthermore, the long retention time (538 days) probably favors frequent cyanobacterial blooms, since it promotes the physical stability of the water column. Pirapora Reservoir showed the highest conductivity values and the lowest water transparency $(0.15 \mathrm{~m})$. In addition, the retention time was short (5 days). These semilotic conditions probably do not favour the growth of the majority of phytoplanktonic groups, including the cyanobacteria. Moreover, a wide oscillation of conductivity values as well as of total nitrogen and phosphorous concentrations was detected along the year (Cetesb 2003). Since cyanobacteria do not tolerate extensive environmental changes, these findings could explain the low species richness of this group in Pirapora Reservoir. Ponte Nova is the only reservoir with low concentrations of total phosphorous and total nitrogen. Carvalho (2003) observed the same
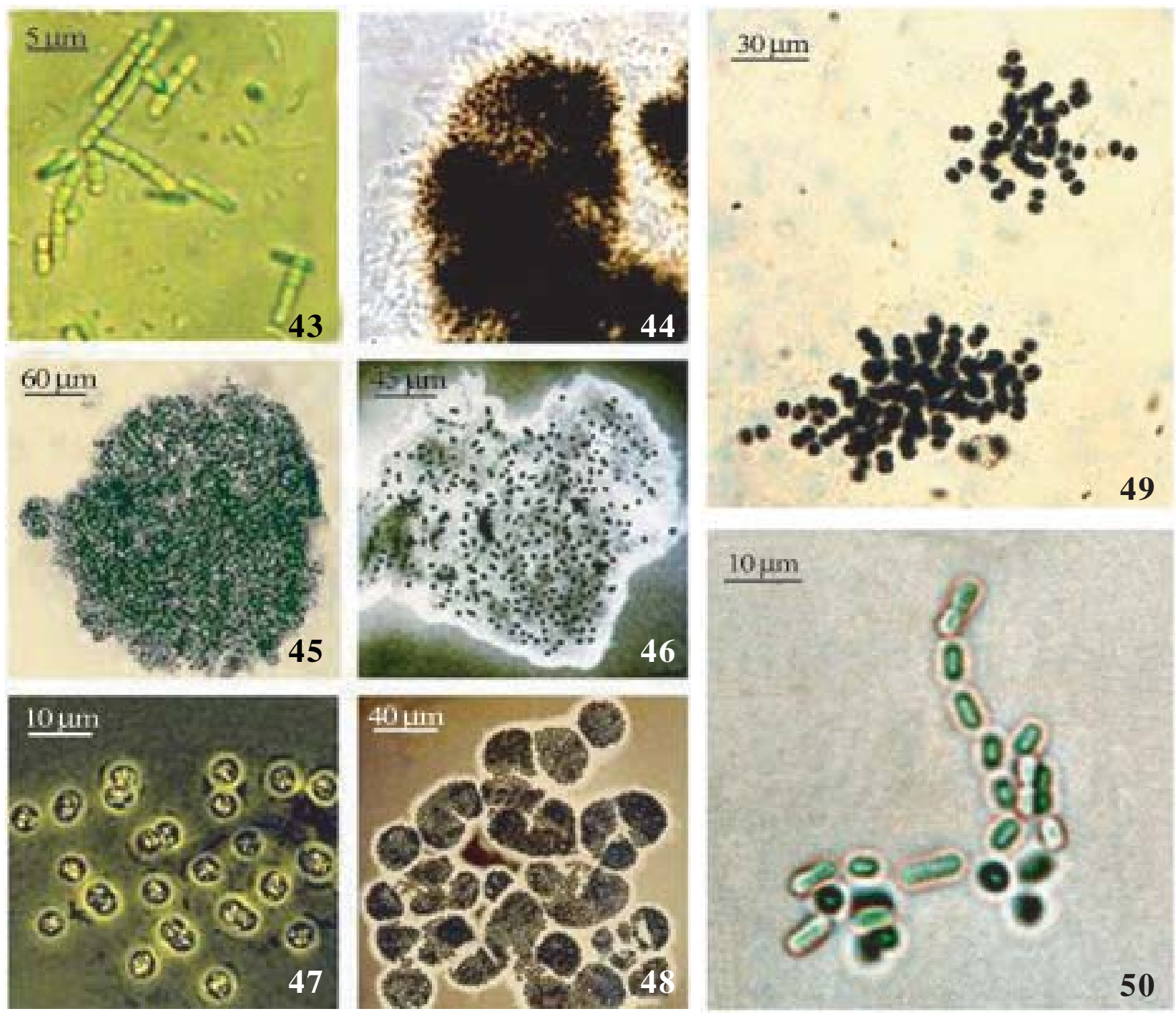

Figures 43-50. Planktic cyanobacteria from upper Tietê basin reservoirs, SP, Brazil. 43. Pseudanabaena mucicola. 44. Microcystis botrys. 45. M. panniformis. 46-47. M. protocystis. 48. M. wesenbergii. 49. Radiocystis fernandoi. 50. Rhabdoderma lineare. 

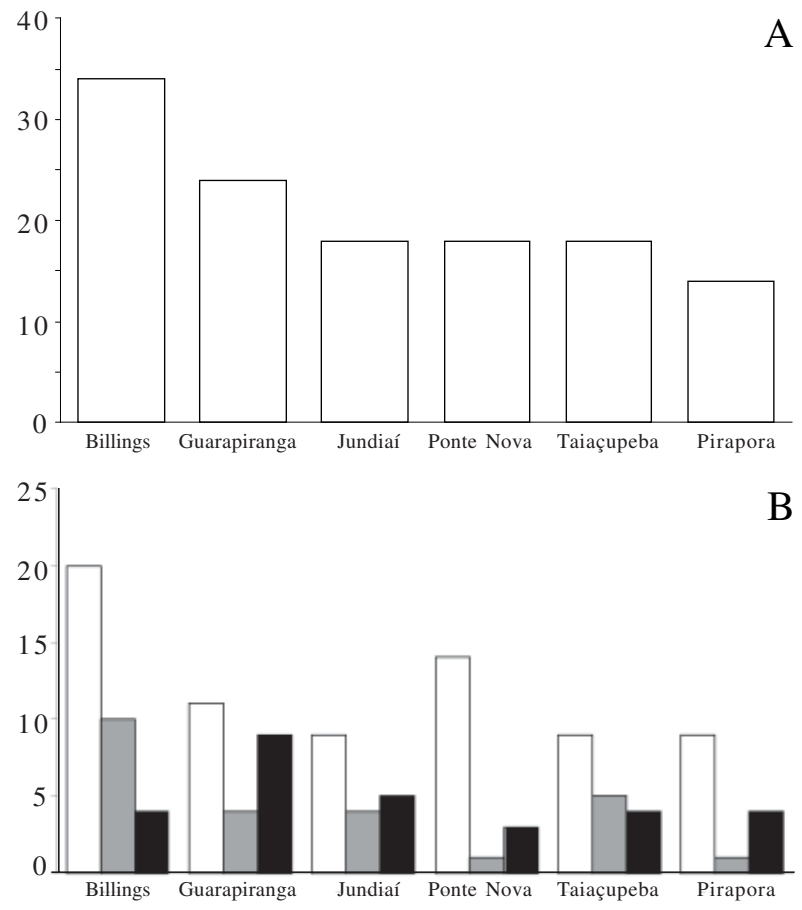

Figure 51. Biodiversity of cyanobacterial groups in the upper Tietê reservoirs. A. Total number of species in each reservoir. B. Number of species of the orders Chroococcales ( $\square$ ), Nostocales $(\square)$ and Oscillatoriales ( $\square)$ in each reservoir. situation and classified the reservoir as oligotrophic based on its phosphorous concentrations and biomass (chlorophyll a).

Among the 48 species, 17 (35\%) were found to be potentially toxic (table 3 ). Coelosphaerium evidenter-marginatum and Sphaerocavum brasiliense, two species recently described in Brazil (Azevedo \& Sant'Anna 1999, 2003), are not toxic. Among the remaining species, there is no information about their toxicity, although some of them are widely distributed in the reservoirs (Aphanocapsa delicatissima, Coelosphaerium tropicalis, Merismopedia tenuissima, Planktolyngbya limnetica and Pseudanabaena species). Along with them, species belonging to the picoplankton and easily neglected in biomonitoring projects, as Aphanocapsa nubilum, Cyanodictyon iac, Epigloeosphaera glebulenta and some Synechococcus species, deserve special attention, particularly when they occur in drinking water reservoirs.

Acknowledgements - The first author thanks CNPq (Proc. $300316 / 81$ ) for the financial support.

Table 3. Cyanobacterial biodiversity and distribution in the upper Tietê reservoirs, SP.

\begin{tabular}{|c|c|c|c|c|c|c|}
\hline Order/Species & $\begin{array}{l}\text { Billings } \\
\text { Reservoir }\end{array}$ & $\begin{array}{c}\text { Guarapiranga } \\
\text { Reservoir }\end{array}$ & $\begin{array}{c}\text { Jundiaí } \\
\text { Reservoir }\end{array}$ & $\begin{array}{l}\text { Pirapora } \\
\text { Reservoir }\end{array}$ & $\begin{array}{c}\text { Ponte Nova } \\
\text { Reservoir }\end{array}$ & $\begin{array}{c}\text { Taiaçupeba } \\
\text { Reservoir }\end{array}$ \\
\hline \multicolumn{7}{|l|}{ CHROOCOCCALES } \\
\hline Aphanocapsa delicatissima & + & + & + & + & + & + \\
\hline A. elachista & + & + & & & + & \\
\hline A. holsatica & + & & & & & \\
\hline A. incerta & & + & & & & \\
\hline A. koordersii & + & & & + & & \\
\hline A. nubilum & & + & & & & \\
\hline A. smithii & & & & & + & \\
\hline Chroococcus dispersus & + & & & & + & \\
\hline C. limneticus & + & & & & + & \\
\hline C. minutus & + & & & + & + & \\
\hline Coelosphaerium evidenter-marginatum & $m+$ & & & & & \\
\hline Coelomoron tropicale & + & + & + & & & + \\
\hline Cyanodyction iac & & & & + & + & \\
\hline Epigloesphaera glebulenta & & & & + & + & \\
\hline Merismopedia punctata & + & + & & & & \\
\hline M. tenuissima & + & + & + & & & + \\
\hline Microcystis aeruginosa* & + & + & + & + & + & + \\
\hline M. botrys* & + & & & & & \\
\hline M. panniformis* & + & + & + & & & $\begin{array}{l}+ \\
\text { continue }\end{array}$ \\
\hline
\end{tabular}


continuation

\begin{tabular}{|c|c|c|c|c|c|c|}
\hline Order/Species & $\begin{array}{l}\text { Billings } \\
\text { Reservoir }\end{array}$ & $\begin{array}{c}\text { Guarapiranga } \\
\text { Reservoir }\end{array}$ & $\begin{array}{c}\text { Jundiaí } \\
\text { Reservoir }\end{array}$ & $\begin{array}{l}\text { Pirapora } \\
\text { Reservoir }\end{array}$ & $\begin{array}{c}\text { Ponte Nova } \\
\text { Reservoir }\end{array}$ & $\begin{array}{c}\text { Taiaçupeba } \\
\text { Reservoir }\end{array}$ \\
\hline M. protocystis* & + & + & + & & & + \\
\hline M. wesenbergii* & & & + & + & + & + \\
\hline Radiocystis fernandoi* & + & + & & & + & + \\
\hline Rhabdoderma lineare & & & & & + & \\
\hline Snowella lacustris & & & + & & & \\
\hline Sphaerocavum brasiliense & + & & + & & & + \\
\hline Synechocystis aquatilis & + & & & + & + & \\
\hline Synechococcus nidulans & + & & & + & + & \\
\hline Woronichinia naegaeliana & + & & & & & \\
\hline \multicolumn{7}{|l|}{ NOSTOCALES } \\
\hline Anabaena circinalis* & + & + & + & & & + \\
\hline A. $\operatorname{crass} a^{*}$ & + & & + & & & + \\
\hline A. planctonica* & + & + & + & & & + \\
\hline A. solitaria* & + & & & & & \\
\hline A. spiroides* & + & + & & & & \\
\hline Aphanizomenon gracile* & + & & & & & \\
\hline A. tropicalis & + & & & & & + \\
\hline Cylindrospermopsis raciborskii* & + & + & + & + & + & + \\
\hline Raphidiopsis brookii* & + & & & & & \\
\hline R. mediterranea* & + & & & & & \\
\hline \multicolumn{7}{|l|}{ OSCILLATORIALES } \\
\hline Geitlerinema amphibium & & + & & & & \\
\hline G. splendidum & & + & & & & \\
\hline G. unigranulatum & & + & + & & & \\
\hline Limnothrix planctonica & + & + & + & + & + & \\
\hline Planktolyngbya limnetica & & + & + & & & + \\
\hline Planktothrix agardhii* & + & + & & + & & + \\
\hline P. mougeotii* & + & & & + & & \\
\hline Pseudanabaena catenata & & + & & + & + & \\
\hline P. galeata & & + & + & & & + \\
\hline P. mucicola & + & + & + & & + & + \\
\hline
\end{tabular}

* potentially toxic species.

\section{References}

AZEVEDO, M.T.P., NOGUEIRA, N.M.C. \& SANT'ANNA, C.L. 1996. Criptógamos do Parque Estadual das Fontes do Ipiranga, São Paulo, SP. Algas 8: Cyanophyceae. Hoehnea 23:1-38.

AZEVEDO, M.T.P., SOUZA, C.A. \& MENEZES, M. 1999. Synechococcaceae (Cyanophyceae/Cyanobacteria) from a tropical brackish water lagoon, Brazil. Algological Studies 94:45-61.

AZEVEDO, M.T.P., SANT'ANNA, C.L., SENNA, P.A.C., KOMÁREK, J. \& KOMARKOVA, J. 2003. Contribution to the microflora of chroococcalean cyanoprokayotes from São Paulo State, Southeast Brazil. Hoehnea 30:285-295.

AZEVEDO, M.T.P. \& SANT'ANNA, C.L. 1999. Coelosphaerium evidenter-marginatum, a new planktic species of Cyanophyceae/Cyanobacteria from São Paulo State, Southeastern Brazil. Algological Studies 94:35-43.
AZEVEDO, M.T.P. \& SANT'ANNA, C.L. 2003. Sphaerocavum brasiliense, a new planktic genus and species of Cyanobacteria from reservoirs of São Paulo State, Brazil. Algological Studies 109:79-92.

BEYRUTH, Z. 1996. Comunidade fitoplanctônica da Represa de Guarapiranga: 1991-1992. Aspectos ecológicos, sanitários e subsídios para reabilitação da qualidade ambiental. Tese de doutorado, Universidade de São Paulo, São Paulo.

BEYRUTH, Z. 2000. Periodic disturbances, trophic gradient and phytoplankton characteristics related to cyanobacterial growth in Guarapiranga reservoir, São Paulo State, Brazil. Hydrobiologia 424:51-65.

BOUVY, M., FALCÃO, D., MARINHO, M., PAGANO, M. \& MOURA, A. 2000. Occurrence of Cylindrospermopsis (Cyanobacteria) in 39 Brazilian tropical reservoirs during the 1998 drought. Aquatic Microbial Ecology 23:13-27. 
CARACO, N. \& MILLER, R. 1998. Direct and indirect effects of $\mathrm{CO}_{2}$ on competition between cyanobacteria and eukaryotic phytoplankton. Canadian Journal of Fisheries and Aquatic Sciences 55:54-62.

CARMICHAEL, W. 1996. Toxic Microcystis and the environment. In Toxic Microcystis (M.F. Watanabe, K.I. Harada, W.W. Carmichael \& H. Fujiki, eds.). CRC Press, Boca Raton. p.1-11.

CARVALHO, M.C. 2003. Comunidade fitoplanctônica como instrumento de biomonitoramento de reservatórios no Estado de São Paulo. Tese de doutorado, Universidade de São Paulo, São Paulo.

CETESB. 1996. Considerações sobre aspectos limnológicos do reservatório Jundiaí. Série Relatórios. Companhia de Tecnologia de Saneamento Ambiental, São Paulo.

CETESB. 1998. Relatório de qualidade de águas interiores do Estado de São Paulo, 1997. Série Relatórios. Companhia de Tecnologia de Saneamento Ambiental, São Paulo.

CETESB. 1999. Relatório de qualidade das águas interiores do Estado de São Paulo, 1998. Série Relatórios. Companhia de Tecnologia de Saneamento Ambiental, São Paulo.

CETESB. 2003. Relatório de qualidade das águas interiores do Estado de São Paulo, 2002. Série Relatórios. Companhia de Tecnologia de Saneamento Ambiental, São Paulo.

CHORUS, I. 2001. Cyanotoxins: occurrences, causes, consequences. Springer, Berlin.

DOKULIL, M.T. \& TEUBNER, K. 2000. Cyanobacterial dominance in lakes. Hydrobiologia 438:1-12.

HUZSAR, V.L.M., SILVA, L.H.S., MARINHO, M., DOMINGOS, P. \& SANT'ANNA, C.L. 2000. Cyanoprokaryote assemblages of eight productive tropical Brazilian waters. Hydrobiologia 424:67-77.

KOMÁREK, J. \& ANAGNOSTIDIS, K. 1989. Modern approach to the classification system of cyanophytes, 4: Nostocales. Algological Studies 56:247-345.

KOMÁREK, J. \& ANAGNOSTIDIS, K. 1999. Cyanoprokaryota, 1: Chroococcales. In Süsswasserflora von Mitteleuropa. (H. Ettl, G. Gardner, H. Heynig \& D. Mollenheuer, eds.). Gustav Fischer, Jena.

KOMÁREK， J. \& ANAGNOSTIDIS， K. 2005. Cyanoprokaryota, 2: Oscillatoriales. In Süsswasserflora von Mitteleuropa. (B. Bündel, L. Krienitz, G. Gärdner \& M. Schagerl, eds.). Elsevier, München.

KOMÁREK, J., AZEVEDO, M.T.P., LEGNEROVÁ, J.K., SANT'ANNA, C.L. \& SENNA, P.A.C. 2002. Two common Microcystis species (Chroococcales, Cyanobacteria) from tropical America, including M. panniformis sp.nov. Cryptogamie Algologie 23:159-177.
KOMÁREK, J. \& KLING, H. 1991. Variation in six planktic cyanophyte genera in Lake Victoria (East Africa). Algological Studies 61:24-45.

KOMÁRKOVÁ-LEGNEROVÁ, J. 1991. Epigloeosphaera, a new cyanophyte genus from Nordic lakes. Algological Studies 62:7-12.

OLIVER, R.L. \& GANF, G.G. 2000. Freshwater blooms. In The Ecology of Cyanobacteria-Their Diversity in Time and Space. (B.A. Whitton \& M. Potts, eds.). Kluwer Academic Publishers, London, p. 149-194.

PERSSON, P.E. 1996. Cyanobacteria and off-flavours. Phycologia, Suppl. 6:168-171.

SANT'ANNA，C.L. \& AZEVEDO, M.T.P. 1995. Oscillatoriaceae (Cyanophyceae) from São Paulo State, Brazil. Nova Hedwigia 60:19-58.

SANT'ANNA, C.L. \& AZEVEDO, M.T.P. 2000. Contribution to the knowledge of potentially toxic cyanobacteria from Brazil. Nova Hedwigia 71:359-385.

SANT'ANNA, C.L., AZEVEDO, M.T.P., SENNA, P.A.C., KOMÁREK, J. \& KOMÁRKOVÁ, J. 2004. Planktic Cyanobacteria from São Paulo State, Brazil: Chroococcales. Revista Brasileira de Botânica 27:213-227.

SHAPIRO, J. 1990. Current beliefs regarding dominance by blue-greens: the case for the importance of $\mathrm{CO}_{2}$ and $\mathrm{pH}$. Verhandlungen der Internationalen Vereinigung für Theoretische und Angewandte Limnologie 24:38-54.

SMITH, V.H. 1983. Low nitrogen to phosphorus ratios favor dominance by blue-green algae in lake phytoplankton. Science 221:669-671.

SMITH, V.H. 1986. Light and nutrient effects on the relative biomass of blue-green algae in lake phytoplankton. Canadian Journal of Fisheries and Aquatic Sciences 43:148-153.

TUNDISI, J.G. 2003. Água no século XXI: enfrentando a escassez. RiMa, São Carlos.

WATSON, S.B., MCCAULEY, E. \& DOWNING, J.A. 1997. Patterns in phytoplankton taxonomic composition across temperate lakes of differing nutrient status. Limnology and Oceanography 42:487-495.

WERNER, V.R. 1988. Cianofíceas planctônicas da Lagoa de Tramandaí e da Lagoa do Armazém, Rio Grande do Sul, Brasil. Iheringia 37:33-70.

WERNER, V.R. 2002. Cyanophyceae/Cyanobacteria no sistema de lagoas e lagunas da planície costeira do Estado do Rio Grande do Sul, Brasil. Tese de doutorado, Universidade Estadual Paulista, Rio Claro. 